\title{
SUPPORTING INFORMATION: Resonance-Promoted Formic Acid Oxidation via Dynamic Electrocatalytic Modulation
}

\author{
Joshua Gopeesingh ${ }^{1}$, M. Alexander Ardagh ${ }^{2,3}$, Manish Shetty ${ }^{2}$, Sean Burke ${ }^{1}$, \\ Paul J. Dauenhauer ${ }^{2,3}$ and Omar A. Abdelrahman ${ }^{1,3 *}$ \\ ${ }^{1}$ Department of Chemical Engineering, University of Massachusetts Amherst, 686 N. Pleasant Street, Amherst, MA \\ 01003. \\ ${ }^{2}$ Department of Chemical Engineering and Materials Science, University of Minnesota, 420 Washington Ave SE, \\ Minneapolis, MN 55455. \\ ${ }^{3}$ Catalysis Center for Energy Innovation, University of Delaware, 150 Academy Street, Newark, Delaware 19716. \\ *Corresponding Author: abdel@umass.edu
}

Section S1. Figure 1 volcano curve data

\begin{tabular}{ccc}
\hline Catalyst & TOF $\left(\mathbf{s}^{\mathbf{1}}\right)^{\mathbf{a}}$ & $\mathbf{d - b a n d ~ c e n t e r ~}(\mathbf{e V})^{\mathbf{b}}$ \\
\hline $\mathrm{Ag}$ & 0.039 & -4.3 \\
$\mathrm{Au}$ & 0.077 & -3.56 \\
$\mathrm{Cu}$ & 32 & -2.67 \\
$\mathrm{Pt}$ & 98 & -2.25 \\
$\mathrm{Pd}$ & 16 & -1.83 \\
$\mathrm{Co}$ & 0.003 & -1.17 \\
$\mathrm{Ni}$ & 9.3 & -1.29 \\
$\mathrm{Fe}$ & 0.022 & -0.92 \\
$\mathrm{Rh}$ & 3.3 & -1.73 \\
\hline
\end{tabular}

a- Experimentally measured TOF at $523 \mathrm{~K}$ and $2000 \mathrm{ppm}$ formic acid by Wachs et. al ${ }^{1}$

b- Computationally calculated d-band center by Nørskov et. $\mathrm{al}^{2}$

Section S2. Electrochemical cell design. In order to ensure that the only observed catalytic activity was as a result of the Pt working electrode, it was required to ensure that all non-Pt materials in contact with the reactant solution were chemically inert. This promoted the design of custom cell fittings, which were machined at University of Massachusetts Amherst Physics machine shop. A 14-20 PTFE plug (Ace Glass Incorporated, 5846-44) was converted into an adapter that would accept a 10-32 male PEEK finger-tight fitting (IDEX, F-120X) for 1/16-inch OD tubing. One of these custom pieces was used for the inlet gas stream which was delivered via a 1/16-inch PEEK tube (Valco, TPK105-5M), this is shown in Figure S1. Another custom piece was used to hold the Pt working electrode; since the electrode was a 1/32-inch OD wire, a 1/16" OD PTFE sleeve (Gamry, 990-00402) with a 1/32-inch ID was placed over the wire to create a gas-tight seal with the 10-32 PEEK finger-tight fitting. This avoided the need for any additional electrical connections other than the Pt itself inside of the electrochemical cell, where alligator clips connected the external portion of the Pt wire to the potentiostat (Figure S2). The Pt coil counter electrode was housed within fritted glass isolation tube with a 14/20 port opening (Pine Research, RRPG32), which allowed a compression seal adapter to provide a gas tight medium for the counter electrode (Ace Glass Incorporated, 8300-07). 

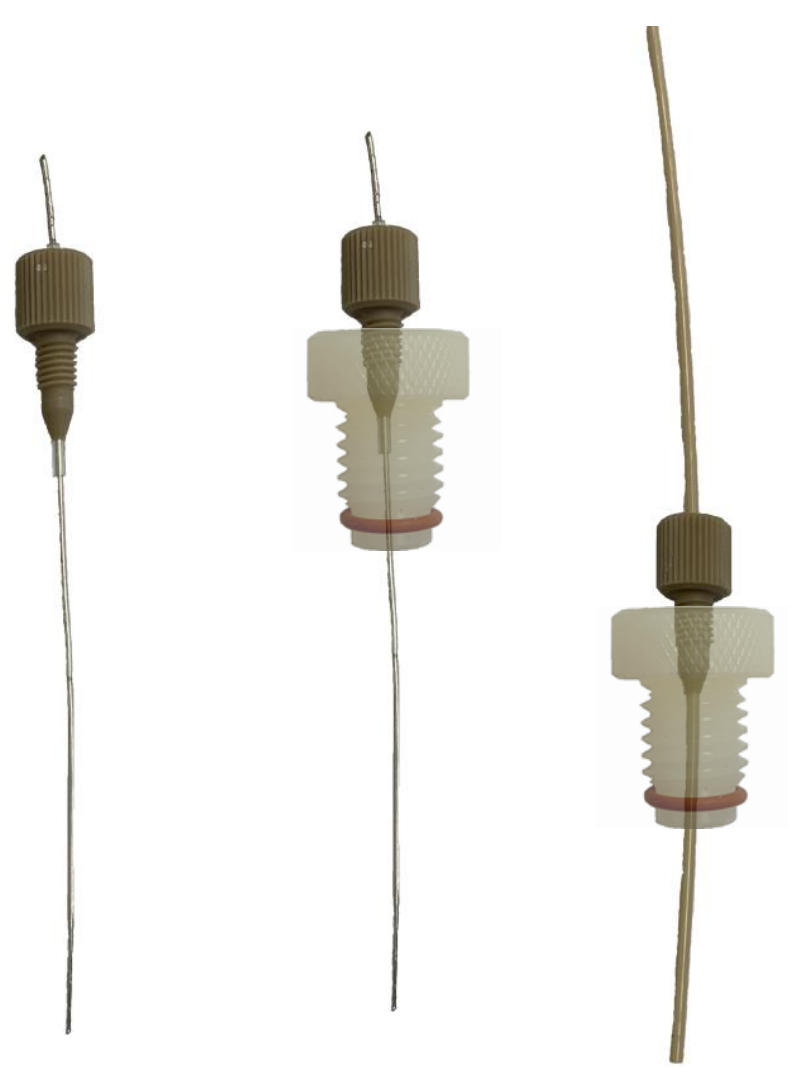

Figure S1. PEEK finger tight fitting for gas tight connections with working electrode and gas feed capillary tubing.
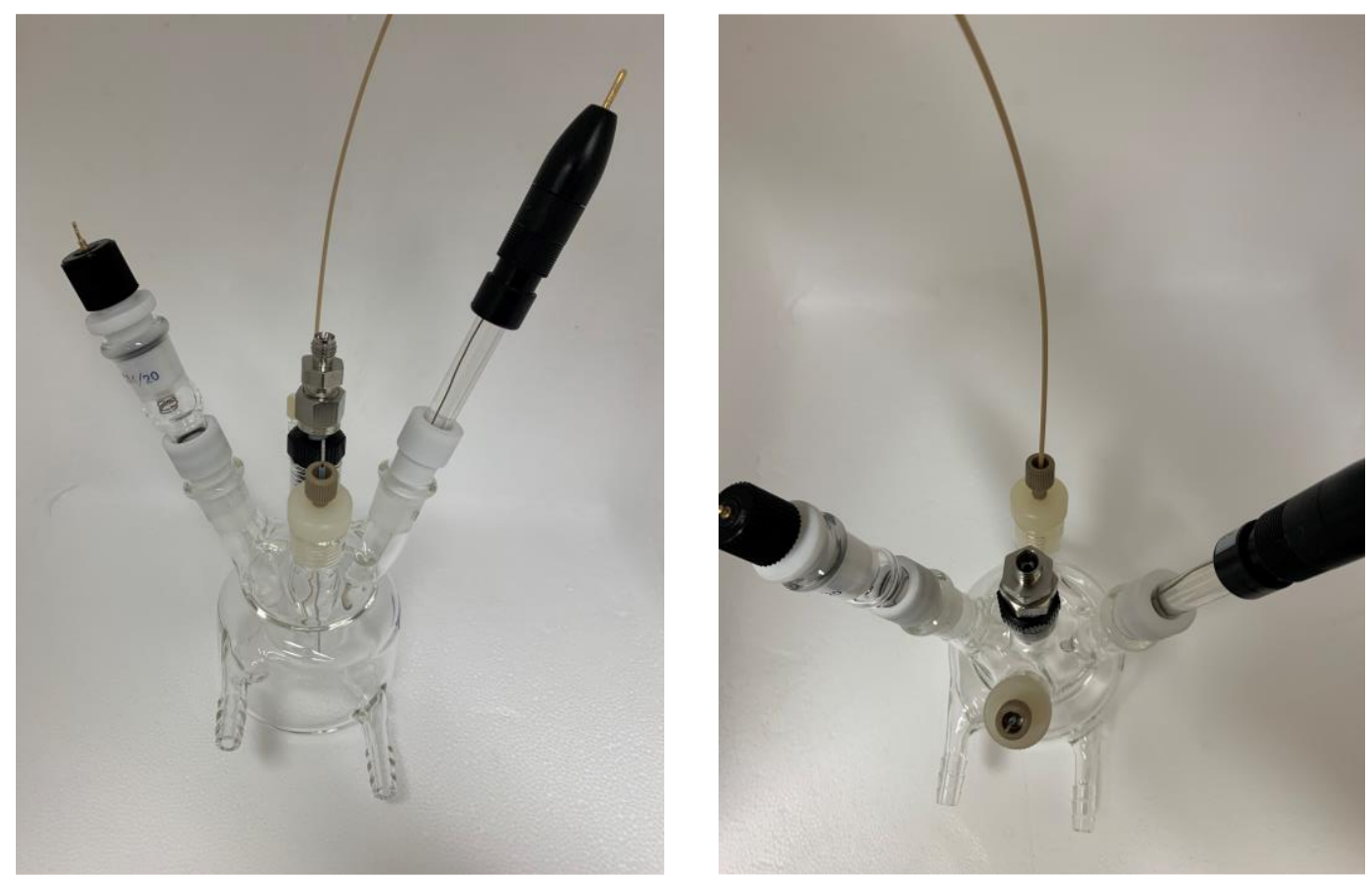

Figure S2. Fully assembled modified electrochemical cell 
Section S3. Residence Time Distribution. The residence time of the electrochemical reactor system as a whole was measured via a residence time distribution (RTD) experiment, where an instantaneous step change from a pure nitrogen stream to one blended with $\mathrm{CO}_{2}$ as a tracer gas was implemented. The switch was facilitated by an electronically actuated (VICI, ED26UWT) twoposition six port valve (VICI, 26UWT). This allowed for a $35 \mathrm{sccm}$ stream of $\mathrm{N}_{2}$ to flow the electrochemical reactor, the effluent of which was blended with a $1.5 \mathrm{sccm}$ stream of $\mathrm{CO}_{2}$ (Bypass mode, Figure S3A) which subsequently passed to an online GC for chemical analysis. Once the $\mathrm{CO}_{2}$ mole fraction ( $\mathrm{y}_{\mathrm{CO} 2}$ ) was found to be stable, the same blended $\mathrm{N}_{2} / \mathrm{CO}_{2}$ stream was passed through the reactor via a switch in the six-port valve (Reactor mode, Figure S3A). The reactor effluent was then sampled every 3.4 minutes via gas chromatography until the mole fraction of $\mathrm{CO}_{2}$ reached that of the reactor feed $\left(\mathrm{ycO}_{\mathrm{CO}} / \mathrm{y}_{\mathrm{CO} 2,0}=1\right.$, Figure S3B). Treating the electrochemical reactor system as a continuously stirred tank reactor (CSTR), the mole fraction of $\mathrm{CO}_{2}$ can be quantitatively described as a function of time,

$$
\frac{\mathrm{y}_{\mathrm{CO}_{2}}}{\mathrm{y}_{\mathrm{CO}_{2}, 0}}=1-\mathrm{e}^{-\frac{\mathrm{t}}{\tau_{\mathrm{r}}}}
$$

where $\tau_{\mathrm{r}}$ is the residence time of the reactor system, which is estimated by a least squares minimization between Eq. S1 and the experimental data (Figure S3B). Based on this approach, we estimate the residence time to be 4.2 mins. We therefore expect the reactor to reach $>99 \%$ of a new steady state value after $\sim 20$ mins from when a step change occurs $\left(5 \tau_{\mathrm{r}}\right)$.

A

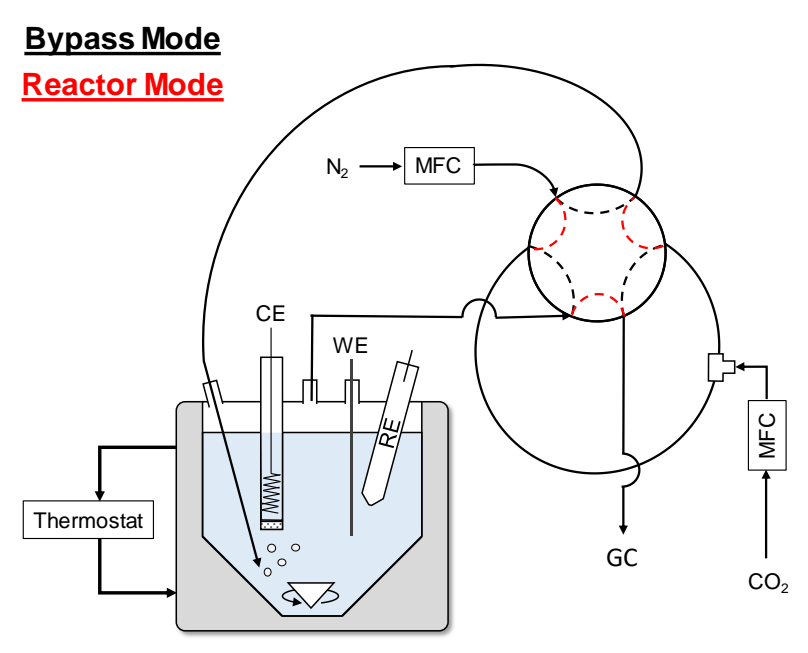

B

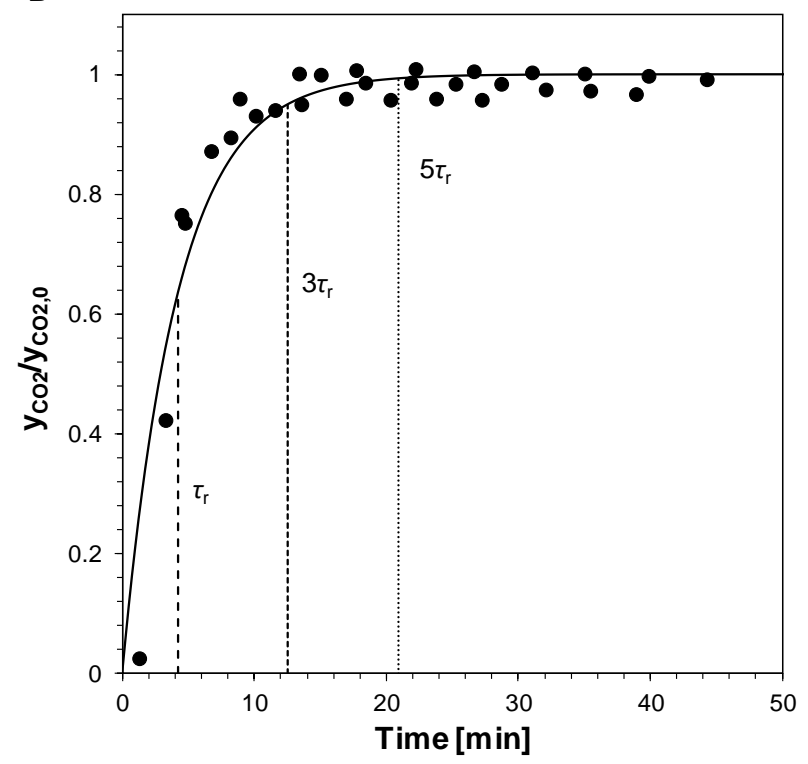

Figure S3. Residence time distribution measurement of electrochemical reactor. (A) Electrochemical reactor setup to create step change in $\mathrm{CO} 2$ concentration by switching between bypass (black) and reactor (red) mode via a two position six-port valve. (B) Experimental (filled symbols) measurement of normalized effluent $\mathrm{CO}_{2}$ mole fraction after a step change from pure nitrogen to a $4.1 \mathrm{~mol} \% \mathrm{CO}_{2}$ feed to the electrochemical reactor. Theoretical prediction of normalized $\mathrm{CO}_{2}$ mole fraction response indicated by solid line (Eq. S1, $\tau_{\mathrm{r}}=4.2 \mathrm{~min}$ ). 
Section S4. Gas Chromatograph Calibration. To accurately quantify the rate of $\mathrm{CO} 2$ formation under reaction conditions, the FID/Jetanizer detector was calibrated using different known concentration of $\mathrm{CO}_{2}$ in $\mathrm{N}_{2}$. Briefly, the flow rate of $\mathrm{CO}_{2}$ and $\mathrm{N}_{2}$ was controlled via two independent mass flow controllers (Brooks Instruments, 5850) to generate the desired mole fraction of $\mathrm{CO}_{2}$. The distinct flow rates were confirmed using a soap bubble flow meter. Three different mole fractions were then analyzed via gas chromatography to measure the relevant $\mathrm{CO}_{2}$ calibration factor (Figure S4).

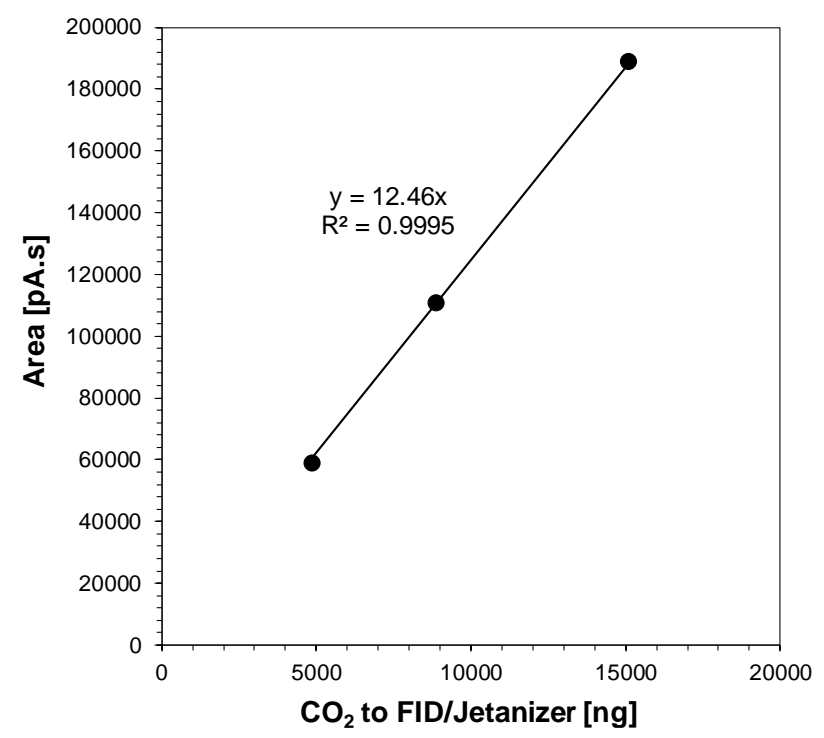

Figure S4. Gas chromatograph $\mathrm{FID} / J e t a n i z e r$ response area to ng of $\mathrm{CO}_{2}$ sent to the detector.

Section S5. Initial Rate Measurement. To be able to accurately account for deactivation as a function of time on stream, it was necessary to first establish an accurate initial rate. This was estimated at $0.8 \mathrm{~V} \mathrm{NHE}$, measuring the rate of reaction every four minutes for approximately one hour. The rates with time on stream were then fit to a first order deactivation model,

$$
\begin{gathered}
\frac{\mathrm{da}}{\mathrm{dt}}=-\mathrm{k}_{\mathrm{d}} \mathrm{a} \\
\ln \mathrm{r}(\mathrm{t})=\ln \left(\mathrm{r}_{0}\right)+\mathrm{e}^{-\mathrm{k}_{\mathrm{d}} \mathrm{t}}
\end{gathered}
$$

where a is the activity defined as the ratio of the rate $(r(t))$ and the initial rate at zero time on stream $\left(\mathrm{r}_{0}\right), \mathrm{k}_{\mathrm{d}}$ is the deactivation rate constant. Through this procedure, the initial rate at zero time on stream over a fresh catalyst could be estimated. Repeated measurements of the initial rate at $0.8 \mathrm{~V}$ NHE revealed a reproducible average of $33.1 \pm 4.0 \mathrm{nmol} \mathrm{CO} \mathrm{min}^{-1}$ over seven repeated regeneration /measurement cycles (Figure S5). 


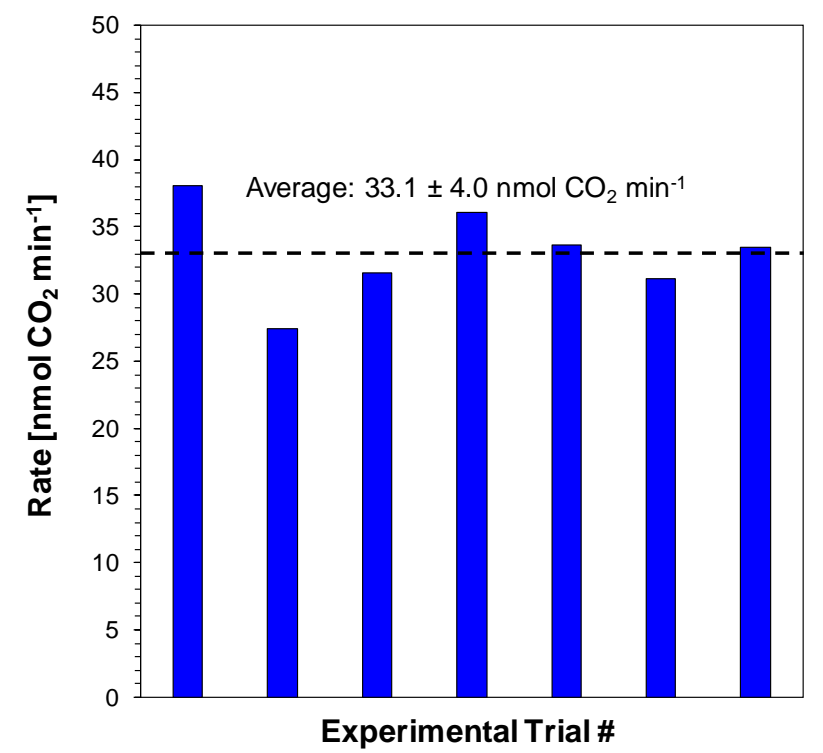

Figure S5. Initial rate estimates at $0.8 \mathrm{~V}$ NHE after thermal reduction of Pt wire at $673 \mathrm{~K}$ in $\mathrm{H}_{2}$. Initial rates were estimated from time on stream rate measurements using a first order deactivation model. $0.25 \mathrm{M}$ formic acid, $0.25 \mathrm{M}$ sulfuric acid at $295 \mathrm{~K}$. Average error estimated at 95\% confidence interval.

Section S6. Cyclic Voltammetry. In order to investigate the state of the platinum working electrode during formic acid electro-oxidation, cyclic voltammetry scans were performed within the range of 0 to $1.2 \mathrm{~V} \mathrm{NHE} \mathrm{(Figure} \mathrm{S6).} \mathrm{Using} \mathrm{a} \mathrm{scan} \mathrm{rate} \mathrm{of} 50 \mathrm{mV} \mathrm{s}^{-1}$ at a step size of $2 \mathrm{mV}$, scans were performed until there was no discernable difference between the 'current vs potential' profiles of consecutive scans; this was done in the presence and absence of formic acid.

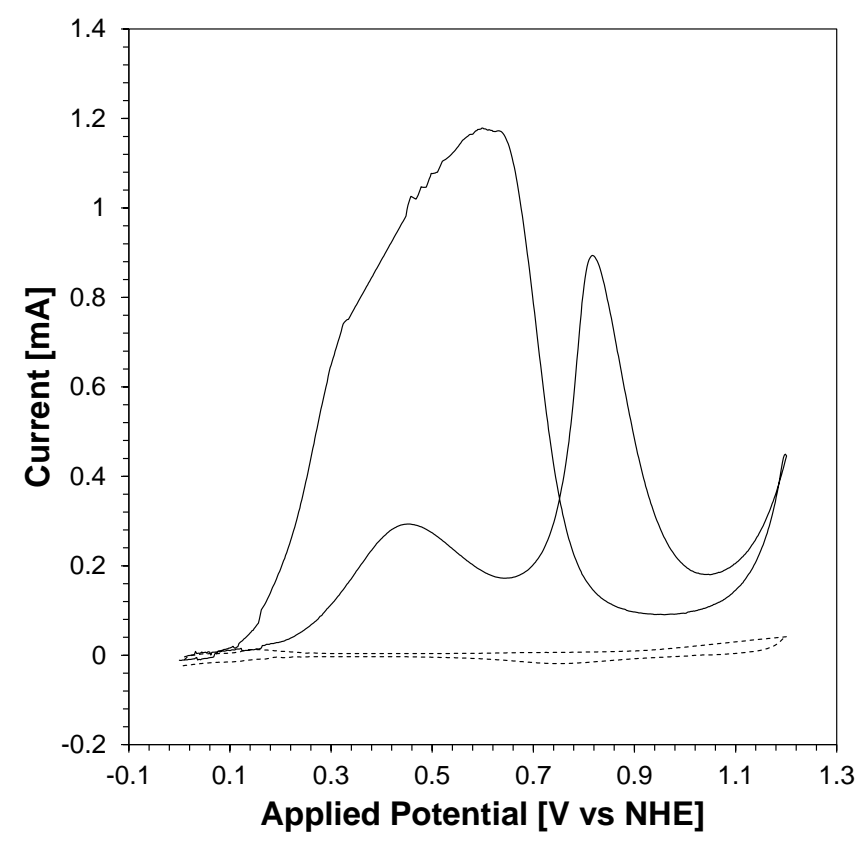

Figure S6. Cyclic voltammetry measurement between 0 and 1.2 V NHE of $0.25 \mathrm{M}$ sulfuric acid solutions with (solid) and without (traced) $0.25 \mathrm{M}$ formic acid. 


\section{Section S7. Open Circuit Potential.}

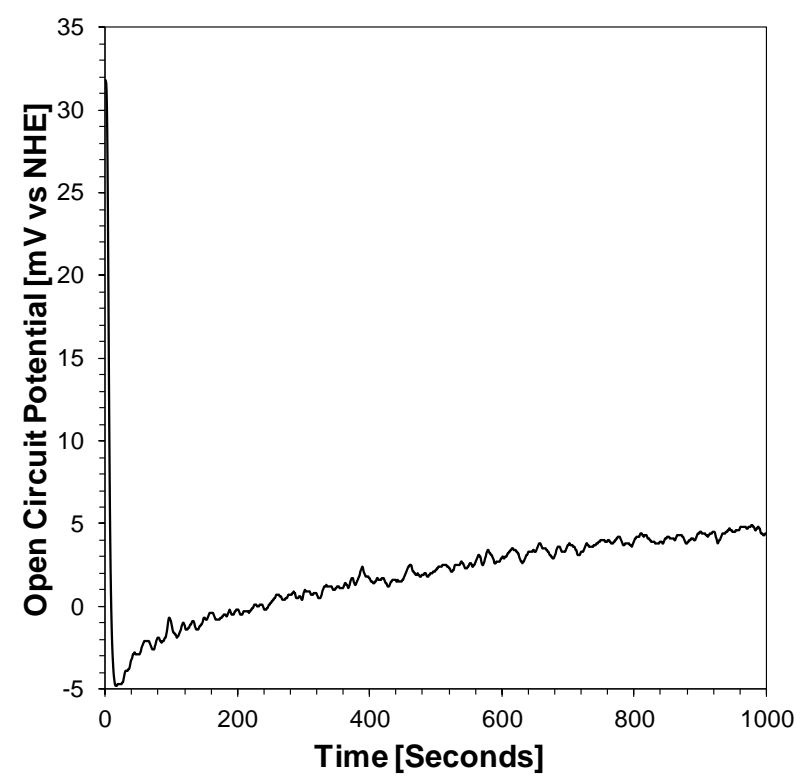

Figure S7. Open circuit potential measurement with $0.25 \mathrm{M}$ formic acid and $0.25 \mathrm{M}$ sulfuric acid.

Section S8. Potentiostatic Electrochemical Impedance Spectroscopy (EIS). It was required to be aware of the resistance of the solution in order to determine whether iR-compensation was required. Perturbations of $10 \mathrm{mV}$ root mean square $\left(\mathrm{rms}, \mathrm{V}_{\mathrm{AC}}\right)$ were applied to a wave form with frequencies varying between 0.1 and $100 \mathrm{kHz}$ and a constant DC offset voltage of $0.8 \mathrm{~V} \mathrm{NHE}$ ( $\mathrm{V}_{\mathrm{DC}}$, Figure S8A); this voltage was chosen because it is the upper oscillation voltage used throughout the study where the highest current was generated. An electrochemical interface can be treated as a resistor (solution resistance) in series with a resistor-capacitor parallel combination (charge transfer resistance-double layer capacitor). At higher oscillation frequencies, the resistance of the solution is the only measured variable. From the generated Bode plot (Figure S8B), a solution resistance (high frequency) of $\sim 2.1 \Omega$ was measured. Taking the highest current observed $(2 \mathrm{~mA})$ as the upper maximum at which the iR-error is the largest, the solution resistance in this instance accounts for $4.2 \mathrm{mV}$ of the applied $0.8 \mathrm{~V}$; an error of less than $1 \%$. 
A

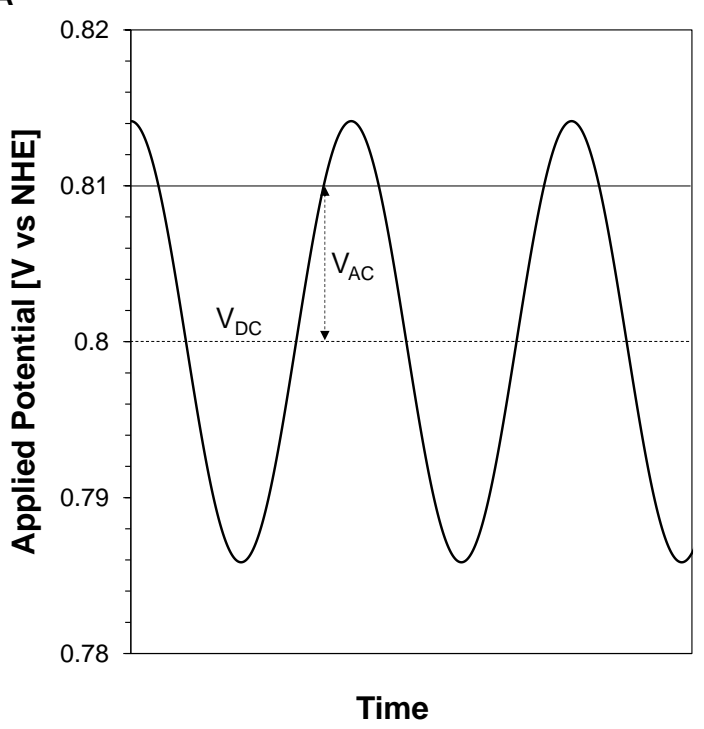

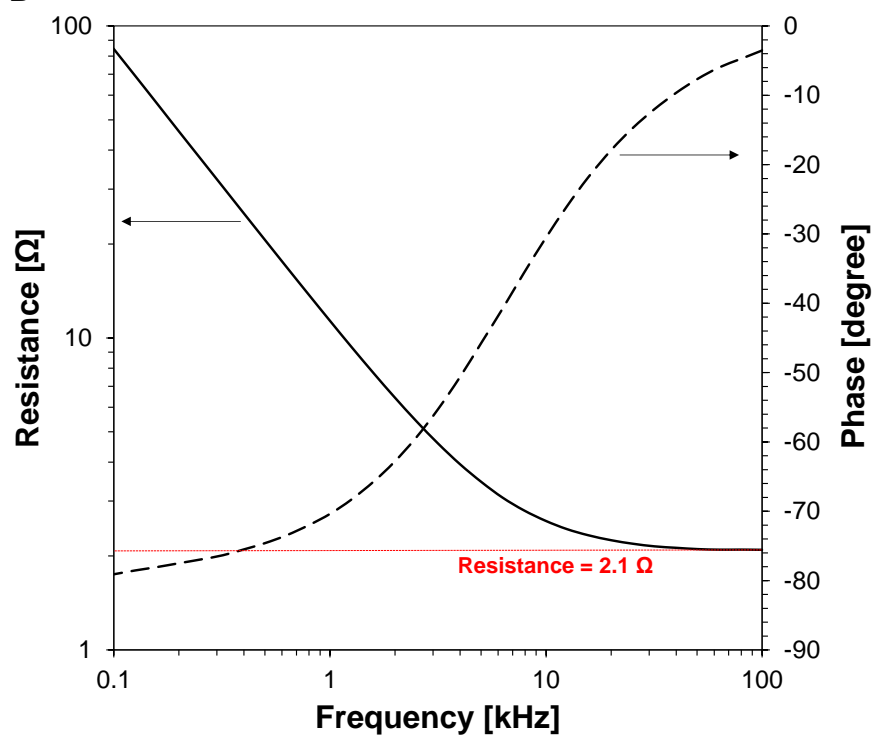

Figure S8 Electrochemical impedance spectroscopy measurements A. Sinewave oscillation with a constant DC offset of $0.8 \mathrm{~V}\left(\mathrm{~V}_{\mathrm{DC}}\right)$ and oscillating $\mathrm{AC}$ voltage of $10 \mathrm{mV} \mathrm{rms}\left(\mathrm{V}_{\mathrm{AC}}\right)$ B. Bode plot for a $0.25 \mathrm{M}$ sulfuric acid. The resistance and phase are represented by the solid and traced lines, respectively.

\section{References}

1. Tang, Y.; Roberts, C. A.; Perkins, R. T.; Wachs, I. E., Revisiting formic acid decomposition on metallic powder catalysts: Exploding the $\mathrm{HCOOH}$ decomposition volcano curve. Surface Science 2016, 650, 103-110.

2. Ruban, A.; Hammer, B.; Stoltze, P.; Skriver, H. L.; Nørskov, J. K., Surface electronic structure and reactivity of transition and noble metals1Communication presented at the First Francqui Colloquium, Brussels, 19-20 February 1996.1. Journal of Molecular Catalysis A: Chemical 1997, 115 (3), 421-429. 